Disponível em

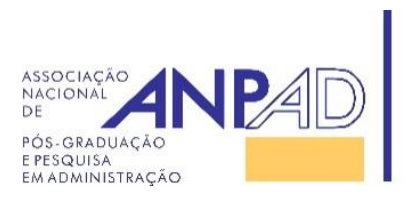

http://www.anpad.org.br/rac

RAC, Rio de Janeiro, v. 21, n. 5, art. 1,

pp. 605-626, Setembro/Outubro, 2017

http://dx.doi.org/10.1590/1982-7849rac2017160145

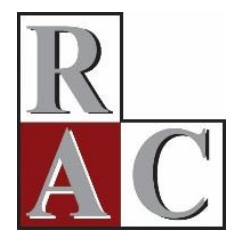

$(\mathrm{coc}) \mathrm{EY}$

\title{
Uso Pessoal das Tecnologias no Trabalho: Motivadores e Efeitos à Distração Profissional
}

Personal Use of Technology at Work: Drivers and Effects on Professional Distraction

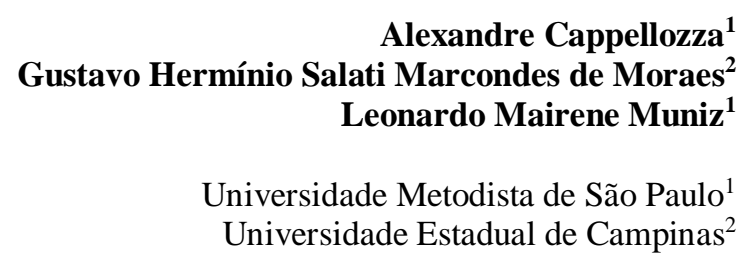

Artigo recebido em 14.06.2016. Última versão recebida em 09.02.2017. Aprovado em 11.02.2017. Publicado online em 25.05.2017. 


\title{
Resumo
}

Apesar dos inúmeros benefícios que as Tecnologias de Informação (TI) - proporcionam a seus usuários, os efeitos adversos da utilização indiscriminada dos dispositivos tecnológicos pessoais no ambiente de trabalho é um tema pouco explorado. Este estudo analisa os aspectos individuais motivadores do uso particular de Tecnologias de Informação no trabalho e a relação da Distração Digital como um componente significativo sobre a perda de atenção dos profissionais durante a execução de suas atividades. A pesquisa evidencia que os aspectos ligados à dependência tecnológica são as principais causas do Uso Pessoal das Tecnologias no ambiente de trabalho. Entre esses motivadores, a perda do Controle do Impulso de uso da TI é o fator mais significativo ao Uso Pessoal das Tecnologias em ambientes profissionais, comparada a outros fatores analisados. A pesquisa também revela que a Distração Digital provoca significativa perda de concentração dos profissionais e que a Utilização Pessoal da TI no ambiente de trabalho é reflexo direto da redução do Engajamento do profissional no seu trabalho. Além disso, o estudo revela que o uso particular das aplicações que promovem interação social não é subterfúgio dos profissionais que manifestaram fraco Suporte Social dos seus pares no local de atuação profissional.

Palavras-chave: tecnologia; dependência; uso excessivo; distração; engajamento.

\begin{abstract}
Despite the numerous benefits that Information Technology (IT) provides to its users, adverse effects from abusive use of personal devices in the workplace remains an unexplored subject. This research examines individual drivers of private use of Information Technologies at work and the relationship that Digital Distraction has as a significant component contributing to professionals' loss of attention during their activities. Our results show that aspects associated with technological dependence are the main influences of personal Use of Technology at Work. Among these aspects, diminished Impulse Control is the most significant factor toward to the use of personal technologies compared to other factors. The research also reveals that digital distraction causes significant loss of professional concentration and that personal use of IT in the workplace is a direct effect of diminished professional engagement. Furthermore, the research reveals that personal use of applications that promote social interaction isn't an escape for professionals who suffer weak Social Support from their peers in the workplace.
\end{abstract}

Key words: technology; dependency; overuse; distraction; engagement. 


\section{Introdução}

As Tecnologias de Informação estão amplamente inseridas no cotidiano do ser humano, facilitando suas atividades rotineiras, seja para trabalhar ou estudar, seja para manter-se informado com relação às notícias de seu interesse, relacionar-se com outras pessoas e comunicar-se com familiares ou amigos (Bargh \& Mckenna, 2004). Em 2015, a quantidade de usuários que utilizaram a Internet por meio de computadores ou dispositivos móveis foi estimada em 3,1 bilhões de pessoas em todo o mundo, o que equivale a 40\% de toda a população global. No Brasil, o total de usuários atingiu 107 milhões de pessoas, o que representa $53 \%$ da população nacional e coloca o país na quinta posição na lista dos que mais acessam a rede, após China, Estados Unidos, Índia e Japão (Emarketer, 2014).

Dentre as causas que explicam o Uso Pessoal e intenso da Tecnologia de Informação (TI), destaca-se a evolução tecnológica dos aparelhos celulares inteligentes, ou smartphones, que proveu a esses dispositivos uma quantidade expressiva de recursos e funções, além de permitir o acesso móvel à rede mundial de computadores (Salehan \& Negahban, 2013). Além disso, a disseminação global dos aparelhos celulares também foi resultado de intensa competitividade entre os atores desse mercado, tais como operadoras de telefonia e fabricantes de aparelhos. Isso permitiu a redução dos valores de aquisição, do acesso à rede e aos terminais (Barifouse, 2015), com absorção dos benefícios de economia de escala pelos usuários.

A facilidade de acesso móvel à Internet, bem como a utilidade e a atratividade dos aplicativos dos smartphones também reforçam a tendência de aumento da frequência e da duração da utilização desses dispositivos. Assim, tornam essas tecnologias indispensáveis na vida cotidiana de muitos usuários, pelos diversos benefícios que as aplicações lhes proporcionam (Salehan \& Negahban, 2013).

Entretanto, apesar dos muitos recursos fornecidos pelas inovações tecnológicas, diversos pesquisadores alertam para as consequências do uso excessivo das Tecnologias de Informação (Brand, Laier, \& Young, 2014; Davis, 2001; Lee, Chuang, \& Cheng, 2014). Esse uso excessivo pode influenciar negativamente a vida pessoal e profissional dos usuários (Salehan \& Negahban, 2013) pela dependência, por vezes viciante (Young, 1998, 2009).

A distração causada pelos meios digitais é um problema potencial que deve ser monitorado nos ambientes organizacionais. A popularidade dos smartphones faz com que tais aparelhos estejam presentes em muitas organizações. Não é raro observar profissionais que utilizam seus dispositivos móveis durante o expediente de trabalho, com intuitos pessoais e de modo abusivo.

Alguns autores afirmam que a falta de Engajamento no Trabalho pode ser um motivador de ações profissionais indesejadas pelos gestores e que favorecem distrações no ambiente profissional (Bakker, Albrecht, \& Leiter, 2011). Há, também, evidências de que deficiências nos relacionamentos sociais podem favorecer o uso excessivo das TIs em ambientes educacionais (Davis, 2001). Outros pesquisadores apontam que os comportamentos abusivos dos usuários são frutos do vício no uso das tecnologias (Young, 1998). No entanto, não há estudos que evidenciem que o uso abusivo de tecnologias no ambiente de trabalho possa ser atribuído a aspectos sociais e motivacionais do comportamento organizacional.

Algumas pesquisas apontam que as distrações causadas pelos recursos tecnológicos podem causar problemas diversos ao usuário, como a perda de foco no trabalho (Suedfeld, 1977), questionamentos por parte dos gestores, e demissões (Goleman, 2013; Shikiar, Halpern, Rentz, \& Khan, 2004; Yao \& Zhong, 2014). Isso indica que o uso abusivo das tecnologias é um fator potencial para perdas organizacionais (Salehan \& Negahban, 2013).

Apesar dos aspectos negativos do Uso Pessoal abusivo das Tecnologias de Informação terem sido apontados em diferentes estudos (Davis, Flett, \& Besser, 2002; Widyanto, Griffiths, \& Brunsden, 2011; Young \& Rogers, 2009), não há estudos que evidenciem o quanto a Distração Profissional pode ser explicada pelas distrações originadas pelos dispositivos digitais pessoais. 
A partir das lacunas de pesquisa apresentadas, este estudo examina a questão sobre quais os papéis dos fatores ligados ao comportamento organizacional, às influências sociais e ao vício tecnológico que potencializam o Uso Pessoal de Tecnologias de Informação durante o expediente de trabalho. Analisa, também, a relação da Distração Digital como componente relativo à perda de atenção dos profissionais.

Esta pesquisa se desenvolve na interseção dos campos de conhecimento de Administração da Informação e Psicologia do Trabalho ao articular conceitos da dependência individual tecnológica e comportamento organizacional. Com isso, atende a interesses teóricos e práticos, ao contribuir para um melhor entendimento teórico das relações que envolvem aspectos individuais associados ao uso particular de Tecnologias de Informação e à perda de atenção dos profissionais no trabalho, além de apresentar sugestões para melhor gestão do uso dos dispositivos tecnológicos privados nos ambientes organizacionais.

\section{Revisão da Literatura}

\section{A dependência individual do uso da TI e seu efeito no trabalho}

Alguns usuários evitam imaginar uma possível ausência do seu smartphone ou a falta de conexão com a Internet em seus negócios ou nas suas vidas privadas. O desconforto exacerbado da ausência potencial dos recursos digitais pode ser considerado indício preliminar de que o usuário está utilizando excessivamente tais recursos (Brand et al., 2014).

Há debate entre estudiosos sobre o enquadramento da dependência severa das tecnologias como uma patologia. Alguns autores relatam que a Psiquiatria considera que o uso excessivo e viciante de uma tecnologia que envolva homem-máquina sem uso de substâncias químicas deve ser classificado como vício comportamental (Armstrong, Phillips, \& Saling, 2000; Widyanto et al., 2011). Dessa forma, o vício em Internet não está relacionado na lista de doenças do Manual de Diagnóstico e Estatística dos Transtornos Mentais (Diagnostic and Statistical Manual of Mental Disorders [DSM]), divulgada pela Associação de Psiquiatria Americana (American Psychiatric Association [APA]). Isso indica que o uso viciante da Internet não é considerado um predisposto para transtornos mentais (APA, 2014; Spada, 2014). Há estudos que associam a dependência do Uso Pessoal de Tecnologias a sintomas negativos ao usuário, como depressão, baixa autoestima, solidão, negligência no trabalho, problemas familiares, dificuldades acadêmicas, sofrimento com isolamento social, além de problemas financeiros (Caplan, 2002; Widyanto et al., 2011; Young \& Rogers, 2009).

Alguns autores definem que o envolvimento cognitivo pleno de um usuário durante a utilização de uma tecnologia perpassa a sensação de fluxo, que é explicada como a concentração e a satisfação absoluta que um indivíduo percebe em uma determinada atividade, e que pode explicar a perda de foco em outras tarefas (Agarwal \& Karahanna, 2000; Koufaris, 2002; Lee \& Chen, 2010).

No contexto profissional, a perda de produtividade pode ser fruto da perda de concentração ocasionada pelas distrações causadas pelo uso dos aplicativos pessoais durante o expediente de trabalho, também denominada Distração Digital (Davis et al., 2002; Goleman, 2013). Embora se espere que o ambiente de trabalho propicie interação social para tratativas de assuntos pertinentes aos negócios, contribua na resolução dos problemas cotidianos e seja um local de concentração coletiva dos colaboradores aplicada às demandas organizacionais, o Uso Pessoal de Tecnologias durante as atividades profissionais pode comprometer as finalizações das demandas existentes. $\mathrm{O}$ foco do usuário deixa de ser o zelo nas atividades organizacionais e sua atenção pode ficar imersa nos conteúdos e nas interações sociais estabelecidas por meio dos aplicativos digitais (Davis et al., 2002; Whitty \& Carr, 2006). Dessa forma, elabora-se:

Hipótese 1 (H1): A Distração Digital influencia positivamente a Distração no Trabalho. 
Outro aspecto que envolve a dependência compulsiva do uso de tecnologias trata da perda de controle sobre o impulso de uso da TI, definida como um sentimento individual obsessivo que torna o usuário incapaz de reduzir a utilização das tecnologias, apesar do desejo de maior controle sobre o uso dos aplicativos ser latente nos seus processos cognitivos (Davis et al., 2002). Sabe-se que usuários compulsivos de TI que apresentam o controle do impulso reduzido sobre a utilização das aplicações tendem a diminuir, subjetivamente, as prioridades para execução de outras atividades, inclusive profissionais, além da busca preferencial do acesso imediato aos meios digitais (Huang \& Leung, 2009; Shikiar et al., 2004).

Nesse sentido, assume-se que a redução de controle do impulso sobre o uso da TI seja um fator presente nos processos cognitivos que influenciem o comportamento individual dos usuários (Davis et al., 2002; Young, 1998), inclusive em locais onde essas pessoas desenvolvem suas atividades profissionais. Portanto, propõe-se a seguinte hipótese:

Hipótese 2: O Controle Reduzido de Impulso influencia positivamente o Uso Pessoal de Tecnologias no Trabalho.

Sabe-se que a dependência excessiva de uso da TI pode levar os usuários a apresentar nomophobia (no mobile phobia). A nomophobia é definida como a ansiedade causada pela ausência do uso do aparelho celular, computador ou qualquer outro dispositivo que permita uma comunicação virtual com outras pessoas (King et al., 2013). Indivíduos que utilizam tecnologias excessivamente também podem apresentar alterações de humor (Caplan, 2002; Huang \& Leung, 2009) e sensações de incômodo quando seu acesso aos aplicativos é interrompido (Widyanto \& McMurran, 2004). Ao contrário, sensações de conforto social são percebidas pelos usuários dependentes quando as conexões virtuais são estabelecidas com fins de relacionamento com outros usuários, em detrimento das relações sociais presenciais (Caplan, 2002; Davis et al., 2002).

Assim, entende-se que o Conforto Online pode ser definido como a percepção de tranquilidade que o usuário nota ao estar conectado em ambientes virtuais para Uso Pessoal e que pode motivar o Uso Pessoal de Tecnologias em ambientes profissionais. Isso permite elaborar a terceira hipótese deste estudo:

Hipótese 3 (H3): Conforto Online impacta positivamente o Uso Pessoal de Tecnologias no Trabalho.

No entanto, a dependência de uso da TI também está associada à tolerância individual sobre o acesso à tecnologia. A tolerância, quando referida a uma dependência de uso de algum artefato viciante, está associada à quantidade de utilização de um determinado objeto orientada à obtenção de um efeito positivo desejado. Por exemplo, sensações de satisfação, prazer ou conforto (Ko et al., 2005; Mak, Lai, Ko, \& Ho, 2014). Sabe-se que a busca por sensações positivas pode levar à perda de controle sobre a utilização desses recursos digitais (Young, 1998, 2009). Isso leva à elaboração da quarta hipótese:

Hipótese 4 (H4): Conforto Online impacta positivamente no Controle Reduzido de Impulso de uso de Tecnologias de Informação.

\section{Relacionamento social e comprometimento profissional, e seus reflexos no Uso Pessoal da TI no Trabalho}

Há estudos que mostram que aspectos sociais promovem o uso excessivo de Tecnologias de Informação sob duas frentes: a busca do conforto social pela manutenção dos relacionamentos nas redes de contato do usuário (Caplan, 2002; Davis et al., 2002), mas também a presença de vínculos socioafetivos fracos com os pares presenciais do usuário. Exemplo: a falta de suporte familiar nas ações individuais cotidianas pode ser um dos fatores que resulte no uso excessivo da Internet (Davis, 2001).

No contexto organizacional, o isolamento social percebido do profissional no ambiente de trabalho é resultado da falta de disponibilidade de suporte e reconhecimento entre os colegas de trabalho, 
além de sensação individual de ausência de integração no time de trabalho (Marshall, Michaels, \& Mulki, 2007).

A alienação, que é uma ausência de Suporte Social, pode ocasionar um aumento da procura de alternativas de socialização, pois pessoas que se sintam fragilizadas emocionalmente tendem a buscar o fortalecimento das relações sociais, por exemplo, com o uso de tecnologias (Huang \& Leung, 2009). Nesse sentido, o Suporte Social percebido no ambiente profissional não deve promover o uso de meios tecnológicos durante o expediente de trabalho. Portanto, propõe-se a seguinte hipótese:

Hipótese 5 (H5): O Suporte Social no Trabalho influencia negativamente o Uso Pessoal de Tecnologias no Trabalho.

Alguns autores afirmam que a falta de envolvimento em atividades da organização, a perda do interesse pessoal na aprendizagem e na obtenção de novas competências profissionais, além da baixa motivação na realização das demandas podem ser fruto do pouco Engajamento do profissional no seu trabalho (Fredricks, Blumenfeld, \& Paris, 2004; Skinner, Furrer, Marchand, \& Kindermann, 2008).

O profissional pouco engajado e insatisfeito com suas atividades pode exibir queda na sua produtividade e na sua eficácia individual (Ghani \& Deshpande, 1994; Maslach \& Leiter, 1997), e comportar-se de modo que suas ações não tenham orientação ao trabalho ou focar em distrações. Por exemplo, pode dedicar-se à cibervadiagem, definida como a utilização indevida dos recursos tecnológicos para fins privados durante o horário de expediente (Greenfield \& Davis, 2002; Whitty \& Carr, 2006), ou a sua distração por meios digitais. Assim, elaboram-se as seguintes hipóteses:

Hipótese 6 (H6): O Engajamento no Trabalho influencia negativamente o Uso Pessoal de Tecnologias no Trabalho.

Hipótese 7 (H7): O Engajamento no Trabalho influencia negativamente a Distração Digital.

A partir das hipóteses elaboradas neste estudo, esquematiza-se o modelo de pesquisa na Figura 1.

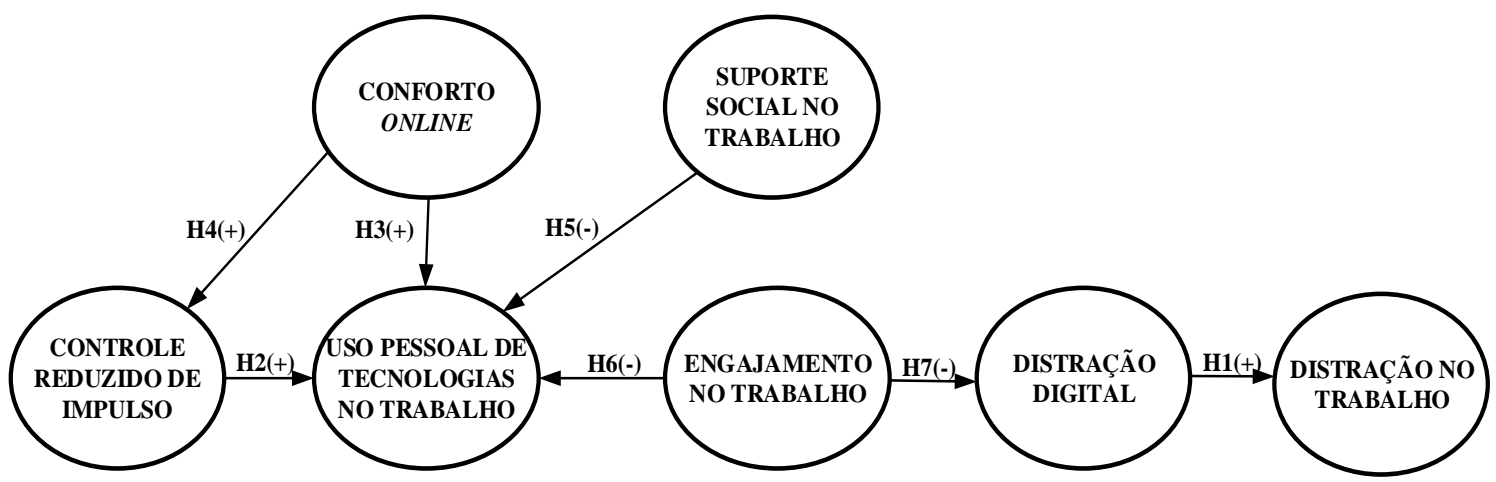

Figura 1. Modelo Conceitual de Pesquisa

\section{Procedimentos Metodológicos}

Este estudo foi desenvolvido sob um paradigma positivista, com posicionamento epistemológico empiricista. Para tanto, foi conduzido por uma abordagem quantitativa de corte transversal único e realizada por meio de survey, que busca, entre outros objetivos, identificar opiniões de grupos específicos e a distribuição do fenômeno na população (Pinsonneault \& Kraemer, 1993), com utilização de técnicas de análise multivariada de dados. 


\section{Operacionalização das variáveis}

A coleta de dados desta pesquisa foi realizada com o auxílio de um questionário com escalas no formato Likert com nove pontos. Os indicadores dos construtos Controle Reduzido de Impulso, Distração Digital e Conforto Online foram obtidos da Escala de Cognição Online (ECO), de Richard Davis, Gordon Flett e Avi Besser (2002), que foi desenvolvida para o estudo de uso problemático da Internet. Os indicadores do construto Distração no Trabalho foram obtidos do instrumento Health and Work Questionnaire (Shikiar et al., 2004).

O estudo de Marshall, Michaels e Mulki (2007) resultou no desenvolvimento da escala de Isolamento no Ambiente de Trabalho, que mensura o isolamento percebido pelo profissional na organização, pelos colegas de trabalho e supervisores, além da falta de oportunidades para uma interação social e emocional com a equipe. Neste estudo, esse construto foi denominado como Suporte Social no Trabalho. Para medição da escala de Uso Pessoal de TI no trabalho, foram elaborados itens que indagavam sobre a frequência de acesso de aplicativos de comunicação, redes sociais, áudio, vídeo, jogos, entretenimento, fotos durante o expediente profissional, além da média de minutos e da frequência de acesso do smartphone para fins pessoais.

Como a escala ECO não havia sido validada em trabalhos no Brasil até o presente estudo, procedeu-se a validação de conteúdo do questionário segundo recomendações de Netemeyer, Bearden e Sharma (2003), na qual os indicadores foram traduzidos por um especialista no idioma das escalas. Em seguida, o instrumento de medida foi analisado por professores pesquisadores de Tecnologia de Informação, que sugeriram ajustes na contextualização de algumas questões. Após essa etapa, o questionário ajustado passou por retrotradução e foi enviado a um nativo no idioma das escalas originais, que não notou diferenças de compreensão sobre as questões originais e as adaptadas dos instrumentos. Os indicadores do instrumento de medida podem ser visualizados na Tabela 1.

Tabela 1

Indicadores das Escalas do Instrumento de Medida

\begin{tabular}{|c|c|c|c|}
\hline CONSTRUTO & INDICADOR & QUESTÃO & REFERÊNCIAS \\
\hline \multirow{3}{*}{$\begin{array}{l}\text { Controle } \\
\text { Reduzido de } \\
\text { Impulso }\end{array}$} & CRI1 & Uso meu smartphone mais do que eu deveria. & \multirow{3}{*}{$\begin{array}{l}\text { Adaptado de } \\
\text { Davis } \text { et al. } \\
\text { (2002) }\end{array}$} \\
\hline & CRI2 & As pessoas reclamam que eu uso muito meu smartphone. & \\
\hline & CRI3 & $\begin{array}{l}\text { Não consigo reduzir o tempo de uso do smartphone } \\
\text { mesmo que, de vez em quando, eu queira. }\end{array}$ & \\
\hline \multirow[t]{4}{*}{$\begin{array}{l}\text { Conforto } \\
\text { Online }\end{array}$} & $\mathrm{CO} 1$ & $\begin{array}{l}\text { Me sinto mais confortável quando estou usando meu } \\
\text { smartphone. }\end{array}$ & \multirow{4}{*}{$\begin{array}{l}\text { Adaptado de } \\
\text { Davis et al. } \\
\text { (2002) }\end{array}$} \\
\hline & $\mathrm{CO} 2$ & $\begin{array}{l}\text { Me sinto mais seguro quando estou usando meu } \\
\text { smartphone. }\end{array}$ & \\
\hline & $\mathrm{CO} 3$ & $\begin{array}{l}\text { Geralmente, encontro paz quando estou usando meu } \\
\text { smartphone. }\end{array}$ & \\
\hline & $\mathrm{CO} 4$ & $\begin{array}{l}\text { Quando estou usando meu smartphone, me considero } \\
\text { livre. }\end{array}$ & \\
\hline \multirow[t]{3}{*}{$\begin{array}{l}\text { Distração } \\
\text { Digital }\end{array}$} & DD1 & $\begin{array}{l}\text { De vez em quando, eu adio outras obrigações por causa } \\
\text { do meu smartphone. }\end{array}$ & \multirow{3}{*}{$\begin{array}{l}\text { Adaptado de } \\
\text { Davis } \text { et al. } \\
\text { (2002) }\end{array}$} \\
\hline & DD2 & Uso meu smartphone para evitar de fazer coisas chatas. & \\
\hline & DD3 & $\begin{array}{l}\text { Usar meu smartphone é uma forma de esquecer as } \\
\text { coisas que devo fazer e não quero. }\end{array}$ & \\
\hline
\end{tabular}


Tabela 1 (continuação)

\begin{tabular}{|c|c|c|c|}
\hline CONSTRUTO & INDICADOR & QUESTÃO & REFERÊNCIAS \\
\hline \multirow{4}{*}{$\begin{array}{l}\text { Distração no } \\
\text { Trabalho }\end{array}$} & DT1 & Sinto-me disperso quando estou no trabalho. & \multirow{4}{*}{$\begin{array}{l}\text { Adaptado de } \\
\text { Shikiar Halpern, } \\
\text { Rentz e Khan } \\
(2004)\end{array}$} \\
\hline & DT2 & Tenho dificuldade em me concentrar no trabalho. & \\
\hline & DT3 & Sinto-me desinteressado com meu trabalho. & \\
\hline & DT4 & Me distraio facilmente quando estou no trabalho & \\
\hline \multirow{5}{*}{$\begin{array}{l}\text { Engajamento } \\
\text { no Trabalho }\end{array}$} & ET1 & Sinto-me revigorado no meu trabalho atual & \multirow{5}{*}{$\begin{array}{l}\text { Siqueira, Martins, } \\
\text { Orengo e Souza } \\
(2014)\end{array}$} \\
\hline & ET2 & $\begin{array}{l}\text { Sinto-me concentrado em minhas tarefas no meu } \\
\text { trabalho }\end{array}$ & \\
\hline & ET3 & Sinto-me disposto no meu trabalho atual & \\
\hline & ET4 & Sinto-me focado no que estou fazendo no meu trabalho & \\
\hline & ET5 & Sinto-me fortalecido no meu trabalho atual & \\
\hline \multirow{3}{*}{$\begin{array}{l}\text { Suporte Social } \\
\text { no Trabalho }\end{array}$} & SS1 & Tenho amigos receptivos no meu trabalho. & \multirow{3}{*}{$\begin{array}{l}\text { Adaptado de } \\
\text { Marshall et al. } \\
\text { (2007) }\end{array}$} \\
\hline & SS2 & $\begin{array}{l}\text { Tenho um, ou mais colegas, com quem eu posso } \\
\text { conversar dos meus problemas do dia a dia no trabalho. }\end{array}$ & \\
\hline & SS3 & $\begin{array}{l}\text { Tenho colegas de trabalho em quem posso confiar se eu } \\
\text { tiver um problema. }\end{array}$ & \\
\hline \multirow[t]{4}{*}{$\begin{array}{l}\text { Uso Pessoal de } \\
\text { TI no trabalho }\end{array}$} & USO1 & $\begin{array}{l}\text { Durante o trabalho, quantas vezes você usa seu } \\
\text { smartphone para fins pessoais? }\end{array}$ & \multirow[t]{4}{*}{$\begin{array}{l}\text { Elaborado pelos } \\
\text { autores }\end{array}$} \\
\hline & & $\begin{array}{l}\text { Durante o trabalho, quantas vezes você acessa os } \\
\text { aplicativos abaixo para fins pessoais? }\end{array}$ & \\
\hline & USO2 & Comunicação (Ex: Whatsapp, Skype, Viber, etc.). & \\
\hline & USO3 & $\begin{array}{l}\text { Redes Sociais (Ex: Facebook, Instagram, Linkedin, } \\
\text { Tinder, etc.). }\end{array}$ & \\
\hline
\end{tabular}

\section{Pré-teste e refinamento das escalas}

De antes da aplicação do questionário até a amostra final, e com o objetivo de observar se as pessoas que participariam da coleta de dados teriam o entendimento pleno das questões, o instrumento de medida foi aplicado, presencialmente, como pré-teste, a um grupo de 150 respondentes. Durante a primeira aplicação do instrumento, não foram manifestadas dúvidas e ambiguidades no preenchimento do questionário. Em seguida, procedeu-se análise exploratória dos indicadores pelo estudo da correlação entre os itens e da correlação item-total corrigida (CITC), que mede a correlação entre os itens do mesmo fator, determinando, assim, até que ponto os indicadores compartilham o mesmo significado (Churchill, 1979). Segundo Simsion (2007), recomenda-se a eliminação de itens que apresentem valores de CITC abaixo de 0,30. Adotando-se este critério, eliminou-se um indicador de cada um dos seguintes construtos: Distração Digital, Conforto Online, Controle Reduzido de Impulso e Uso Pessoal de Tecnologia de Informação.

$\mathrm{Na}$ etapa seguinte, conduziu-se análise fatorial exploratória para identificar se os indicadores possuem correlação entre as variáveis latentes (fatores). O método escolhido para determinar os fatores foi a Análise de Componentes Principais somada ao método de rotação oblíqua. Nessa etapa, busca-se que a carga fatorial de cada indicador atinja valor acima de 0,70. Além disso, espera-se que haja diferença de carga fatorial superior a 0,20 nos construtos adjacentes e que a comunalidade de cada indicador possua valor acima de 0,50 (Hair, Black, Babin, Anderson, \& Tatham, 2009). Após a realização da análise fatorial exploratória, foram eliminados indicadores de todos os construtos por falhas na validação divergente ou por comunalidade reduzida. Entretanto, a exclusão de alguns 
indicadores não feriu a recomendação de Werts, Linn e Jöreskog (1974), que preconiza a manutenção mínima de três itens por construto, para que haja graus de liberdade satisfatórios para execução da análise fatorial, bem como para verificação da unidimensionalidade dos construtos. O teste de esfericidade de Bartlett também foi conduzido com valor da significância nulo em conjunto com o cálculo da medida de adequação da amostra Kaiser-Meyer-Olkin, cujo índice foi igual a 0,85. Esse valor é considerado satisfatório para o prosseguimento das análises (Hair et al., 2009).

Em seguida, verificou-se a consistência interna dos construtos. Um alto valor de consistência interna no construto indica que todas as variáveis representam o mesmo construto latente. A consistência interna é avaliada por meio do Alfa de Cronbach. Para estudos exploratórios, valores entre 0,60 e 0,70 são considerados aceitáveis (Hair, Hult, Ringle, \& Sarstedt, 2014; Nunally \& Berstein, 1994). Na Tabela 2, apresentam-se os resultados comparados da análise de confiabilidade dos indicadores durante o processo de refinamento das escalas.

Tabela 2

Análise de Confiabilidade e Correlações Item-Total dos Construtos

\begin{tabular}{lccccc}
\hline Construtos & $\begin{array}{c}\text { Alfa de } \\
\text { Cronbach } \\
\text { (antes dos } \\
\text { ajustes) }\end{array}$ & $\begin{array}{c}\text { Alfa de } \\
\text { Cronbach } \\
\text { (depois dos } \\
\text { ajustes) }\end{array}$ & $\begin{array}{c}\text { Quantidade de } \\
\text { Itens }\end{array}$ & $\begin{array}{c}\text { CITC } \\
\text { (antes dos } \\
\text { ajustes) }\end{array}$ & $\begin{array}{c}\text { CITC } \\
\text { (depois dos } \\
\text { ajustes) }\end{array}$ \\
\hline Controle Reduzido de Impulso & 0,83 & 0,71 & 3 & $0,29-0,69$ & $0,51-0,58$ \\
Conforto Online & 0,84 & 0,83 & 4 & $0,30-0,70$ & $0,55-0,64$ \\
Distração Digital & 0,75 & 0,76 & 3 & $0,26-0,63$ & $0,58-0,61$ \\
Distração no Trabalho & 0,82 & 0,81 & 4 & $0,46-0,66$ & $0,60-0,72$ \\
Engajamento no Trabalho & 0,90 & 0,88 & 5 & $0,51-0,80$ & $0,67-0,75$ \\
Suporte Social & 0,78 & 0,83 & 3 & $0,44-0,66$ & $0,62-0,69$ \\
Uso de TI no trabalho & 0,77 & 0,76 & 3 & $0,26-0,63$ & $0,56-0,69$ \\
\hline
\end{tabular}

De acordo com os resultados da Tabela 2, observa-se que, apesar da exclusão de alguns indicadores para composição do instrumento de medida final, os valores de Alfa de Cronbach dos construtos permanecem satisfatórios, além da notável melhoria nas correlações item-total dos indicadores contidos no instrumento de coleta para amostra final. Tais resultados, obtidos até esta etapa na pesquisa, asseguram a utilização do instrumento de medida ajustado para coleta de dados na amostra final.

\section{Informações da amostra e coleta de dados}

Para avaliar o tamanho da amostra deste estudo e o poder estatístico das análises, utilizou-se o software G*Power 3.1 (Faul, Erdfelder, Buchner, \& Lang, 2009), de acordo com as recomendações de Hair, Hult, Ringle e Sarstedt (2014).

Considerando-se quatro variáveis preditoras ao construto uso de TI, sob nível de significância de $5 \%$, poder estatístico de 0,8 e tamanho do efeito médio ( $\mathrm{f}^{2}=0,15$, que equivale a $\mathrm{r}^{2}=13 \%$ ), obteve-se que o tamanho mínimo da amostra é igual a 85 respondentes. A coleta de dados foi realizada presencialmente, com a participação voluntária dos respondentes em duas empresas e em cursos de pósgraduação de quatro instituições de ensino superior no Estado de São Paulo, selecionadas por conveniência e que permitiram o acesso aos respondentes pelos pesquisadores. O questionário foi impresso e aplicado a 415 pessoas que utilizam aplicativos para fins pessoais durante o expediente de trabalho, e 104 questionários incompletos foram descartados das análises finais. Portanto, a amostra utilizada neste estudo contemplou 311 observações. Dentre a amostra coletada, obtiveram-se $67,8 \%$ da 
amostra com respondentes do gênero masculino (211 pessoas) e 32,2\% de respondentes do gênero feminino (100 pessoas). Em relação à faixa etária dos respondentes, observou-se que a média de idade dos participantes é igual a 23 anos, com desvio padrão de 5,65 anos, e que todos estavam empregados no momento da aplicação do instrumento de coleta.

\section{Resultados Descritivos do Uso Pessoal de TI no Trabalho}

Os resultados do estudo mostram que $87,5 \%$ dos usuários utilizam, durante o expediente de trabalho, aplicativos de comunicação, tais como: Whatsapp, Skype e outros. Além disso, $51,40 \%$ dos respondentes informaram que utilizam os aplicativos de comunicação instantânea oito vezes, ou mais, durante o expediente.

O acesso a redes sociais pelos usuários durante a execução das atividades profissionais também é significativo: 70,42\% dos respondentes informaram que acessam as redes sociais durante a jornada de trabalho, e 19\% informaram que acessam as redes sociais oito vezes, ou mais, durante o expediente.

Também se observou que, para Distração no Trabalho, os jogos são acessados por 76,85\% dos respondentes, e os aplicativos de vídeo são acessados por $63,67 \%$ dos respondentes. A preferência de uso dos aplicativos de comunicação em relação a outros aplicativos de entretenimento neste estudo se assemelha a outras pesquisas que afirmam que os serviços digitais de comunicação são as aplicações favoritas na preferência dos usuários, entre outros tipos de aplicativos (Sultan, 2014).

Os resultados do estudo também mostram que a utilização dos smartphones com fins pessoais durante as atividades profissionais é alta: somente $10,61 \%$ dos respondentes informaram que não utilizam seus terminais durante o expediente, enquanto 30,23\% dos respondentes acessam seus smartphones oito vezes, ou mais. Isso confirma outros estudos (Greenfield \& Davis, 2002) que identificam que a maioria expressiva dos funcionários utilizam Tecnologias de Informação para fins pessoais no trabalho. No entanto, apesar do uso do smartphone ser frequente nos ambientes organizacionais, o tempo médio por acesso ao smartphone não é superior a três minutos por utilização para 59,48\% dos respondentes. Isso denota que a Distração Digital é, relativamente, rápida e habitual entre os participantes.

\section{Análise das hipóteses}

De acordo com as sugestões de Hair et al. (2014), quando os objetivos do estudo convergem na predição e na explicação dos construtos do objeto de pesquisa, sugere-se a utilização de modelagem por equações estruturais, por Partial Least Squares Path Modeling (PLS-SEM). Para os cálculos e validações dos testes estatísticos, foi utilizado o software SmartPLS 3.0.M3 (Ringle, Wende, \& Becker, 2015).

Para definição do modelo de mensuração do estudo, os indicadores foram orientados como reflexivos, de acordo com os estudos originais das escalas que prescrevem as manifestações dos construtos pelos seus respectivos indicadores (Jarvis, Mackenzie, \& Podsakoff, 2003). Os valores significativos das intercorrelações dos itens de cada dimensão reforçam, empiricamente, a orientação reflexiva dos indicadores, além dos valores satisfatórios obtidos na avaliação do modelo de mensuração (Churchill, 1979; Diamantopoulos \& Siguaw, 2006). Os critérios para avaliação de modelos de mensuração reflexivos, de acordo com Hair et al. (2014), são: consistência interna (confiabilidade composta); confiabilidade do indicador; validade convergente (variância média extraída); validade discriminante.

As validades discriminante e convergente foram avaliadas no nível dos indicadores e das variáveis latentes. Quase todos os indicadores apresentaram cargas fatoriais altas em suas variáveis latentes, superiores a 0,70, e cargas fatoriais baixas nas demais variáveis latentes, indicando razoável validade 
convergente e divergente (Chin, 1998). Indicadores que apresentaram cargas fatoriais baixas em suas variáveis latentes ou altas em outras variáveis latentes foram eliminados das análises posteriores, de acordo com as sugestões de Hair et al. (2014). Outro indicador utilizado para a validação convergente do modelo é o valor da variância média extraída (AVE), que deve apresentar valor superior a 0,5 (Hair et al., 2014). Para avaliar o modelo de mensuração, além do exame das cargas para cada indicador, verificou-se a confiabilidade composta de cada construto (Hair et al., 2014). Um valor de referência comumente referido para confiabilidade aceitável é igual a 0,70. Os valores dessas métricas estão apresentados na Tabela 3, e indicam que os resultados são satisfatórios para continuidade das análises.

Tabela 3

\section{Síntese da Avaliação dos Modelos de Mensuração}

\begin{tabular}{lllc}
\hline Construtos & $\begin{array}{l}\text { Variância Média } \\
\text { Extraída dos construtos }\end{array}$ & $\begin{array}{l}\text { Confiabilidade } \\
\text { Composta }\end{array}$ & $\mathrm{R}^{2}$ \\
\hline Controle Reduzido de Impulso & 0,64 & 0,84 & 0,24 \\
Conforto Online & 0,66 & 0,89 & \\
Distração Digital & 0,68 & 0,86 & 0,10 \\
Distração no Trabalho & 0,65 & 0,87 & 0,40 \\
Engajamento no Trabalho & 0,67 & 0,91 & \\
Suporte Social no Trabalho & 0,59 & 0,81 & 0,13 \\
Uso de TI pessoal no trabalho & 0,68 & 0,86 & \\
\hline
\end{tabular}

Para avaliar o coeficiente de determinação $\left(\mathrm{r}^{2}\right)$, utilizou-se o estudo de Cohen (1988) que determina que os valores de $\mathrm{f} 2$ iguais a $0,02,0,15$ e 0,35 são considerados, respectivamente, como efeitos pequenos, médios e grandes. Esses valores de f2 representam valores de $\mathrm{r} 2$ iguais a $2 \%, 13 \%$ e $25 \%$, respectivamente. As análises post hoc mostram que o $\mathrm{r}^{2}$ superior a $3,74 \%$ é significante sob o poder estatístico e o nível de significância estabelecidos para o cálculo do tamanho mínimo da amostra; além disso, o poder obtido foi igual a 0,99 e é considerado adequado para o tamanho de efeito médio (Chin \& Newsted, 1999; Hair et al., 2014).

De acordo com os resultados da Tabela 3, os construtos Controle Reduzido de Impulso e Distração no Trabalho apresentaram um $\mathrm{r}^{2}$ com efeito considerado alto, enquanto o construto Uso Pessoal de TI apresenta um $\mathrm{r}^{2}$ com efeito considerado médio.

Outro indicador de validade discriminante entre os construtos é calcular a raiz quadrada da variância média extraída dos construtos. Esse valor deve ser maior que a correlação entre as variáveis latentes (Fornell \& Larcker, 1981). A Tabela 3 apresenta esses valores obtidos pela amostra deste estudo. $\mathrm{Na}$ diagonal, em negrito, é apresentada a raiz quadrada da variância média extraída, que é superior à correlação das variáveis latentes em todos os casos. 
Tabela 4

Matriz de Correlações e Raiz Quadrada da Variância Média Extraída

\begin{tabular}{lccccccc}
\hline \multicolumn{1}{c}{ Construtos } & $\begin{array}{c}\text { Controle } \\
\text { Reduzido } \\
\text { de } \\
\text { Impulso }\end{array}$ & $\begin{array}{c}\text { Conforto } \\
\text { Online }\end{array}$ & $\begin{array}{c}\text { Distração } \\
\text { Digital }\end{array}$ & $\begin{array}{c}\text { Distração } \\
\text { no } \\
\text { Trabalho }\end{array}$ & $\begin{array}{c}\text { Engajamento } \\
\text { no } \\
\text { Trabalho }\end{array}$ & $\begin{array}{c}\text { Suporte } \\
\text { Social no } \\
\text { Trabalho }\end{array}$ & $\begin{array}{c}\text { Uso de TI } \\
\text { pessoal no } \\
\text { trabalho }\end{array}$ \\
\hline Controle Reduzido de Impulso & 0,80 & & & & & & \\
Conforto Online & 0,49 & 0,81 & & & & & \\
Distração Digital & 0,50 & 0,51 & 0,82 & & & & \\
Distração no Trabalho & 0,42 & 0,31 & 0,52 & 0,80 & & & \\
Engajamento no Trabalho & $-0,19$ & $-0,04$ & $-0,32$ & $-0,50$ & 0,82 & & \\
Suporte Social no Trabalho & 0,09 & 0,14 & 0,11 & $-0,05$ & 0,16 & 0,77 & \\
Uso de TI pessoal no trabalho & 0,32 & 0,16 & 0,19 & 0,21 & $-0,22$ & 0,12 & 0,82 \\
\hline
\end{tabular}

Para analisar as significâncias dos indicadores, foi utilizada a técnica bootstrapping (Efron \& Tibshirani, 1998). De acordo com as recomendações de Hair et al. (2014), foi realizada uma reamostragem de 5.000 amostras. Após a execução dos cálculos nesta amostra, os valores das cargas de todos os indicadores foram considerados significantes, de acordo com as recomendações de Efron e Tibshirani (1998) e Hair et al. (2014).

Para avaliar se existem problemas de colinearidade no modelo estrutural, foram analisados os valores do fator de inflação da variância - FIV para cada construto do modelo estrutural. Os resultados obtidos estão dentro da faixa de valores estabelecida por Hair et al. (2014), que recomenda que o FIV seja inferior a 5. Os valores de FIV dos relacionamentos entre construtos são apresentados na Tabela 5. Esta tabela também apresenta os valores dos coeficientes entre os construtos e as respectivas estatísticas $\mathrm{t}$ de Student. Os valores dos coeficientes também foram estimados pela técnica de bootstrapping. Todos os valores dos relacionamentos apresentaram valores de t de Student superiores a 1,96 e são considerados significantes, com exceção dos relacionamentos entre Conforto Online e Uso e entre Suporte Social no Trabalho e Uso.

Tabela 5

\section{Coeficientes do Modelo Estrutural - Entre Construtos}

\begin{tabular}{lccccc}
\hline Relacionamentos & $\begin{array}{c}\text { Coeficientes } \\
\text { (Média) }\end{array}$ & $\begin{array}{c}\text { Desvio } \\
\text { Padrão }\end{array}$ & $\begin{array}{c}\text { Estatística } \\
\text { T }\end{array}$ & $\begin{array}{c}\text { p-valor } \\
\text { (bi-caudal) }\end{array}$ & FIV \\
\hline Controle Reduzido de Impulso $\rightarrow$ Uso de TI & 0,27 & 0,06 & 4,21 & 0,00 & 1,37 \\
Conforto Online $\rightarrow$ Controle Reduzido de Impulso & 0,49 & 0,05 & 10,19 & 0,00 & 1,00 \\
Conforto Online $\rightarrow$ Uso de TI & 0,01 & 0,06 & 0,10 & 0,92 & 1,33 \\
Distração Digital $\rightarrow$ Distração no Trabalho & 0,41 & 0,06 & 6,60 & 0,00 & 1,12 \\
Engajamento no Trabalho $\rightarrow$ Distração Digital & $-0,33$ & 0,06 & 5,46 & 0,00 & 1,00 \\
Engajamento no Trabalho $\rightarrow$ Distração no Trabalho & $-0,37$ & 0,05 & 7,33 & 0,00 & 1,12 \\
Engajamento no Trabalho $\rightarrow$ Uso de TI & $-0,19$ & 0,06 & 3,18 & 0,00 & 1,07 \\
Suporte Social no Trabalho $\rightarrow$ Uso de TI & 0,14 & 0,07 & 1,76 & 0,08 & 1,05 \\
\hline
\end{tabular}

Assim, de acordo com os resultados da Tabela 5, pode-se afirmar que o Engajamento no Trabalho influencia diretamente o Uso Pessoal de TI e a Distração no Trabalho de forma negativa. Isso revela que 
profissionais engajados nos seus afazeres profissionais tendem a reduzir desvios de concentração e foco nas suas atividades laborais pelo uso pessoal de seus dispositivos pessoais.

De acordo com Cronbach e Meehl (1955), recomenda-se a validação nomológica como uma das formas para evidenciar se as medidas utilizadas são válidas. Nessa direção, testou-se o relacionamento entre o construto Engajamento com a Distração no Trabalho e os resultados obtidos na Tabela 5 confirmam que o Engajamento profissional influencia negativamente as distrações durante o expediente profissional. Esses resultados estão de acordo com outros estudos que teorizam sobre os efeitos do Engajamento no ambiente profissional (Ghani \& Deshpande, 1994; Maslach \& Leiter, 1997).

Os resultados também apontam que o Suporte Social no Trabalho não possui relação significante com o Uso Pessoal de TI no trabalho e, portanto, não se pode afirmar que a baixa integração social do colaborador com os membros do grupo favoreça o uso pessoal e indiscriminado de TI. Nesse sentido, este resultado se alinha aos resultados de outros autores que afirmam que indivíduos que sofrem alienação dos seus pares podem, inclusive, reduzir o uso de ferramentas de comunicação no desenvolvimento de suas atividades (Huang \& Leung, 2009).

A redução do controle sobre o impulso de Uso Pessoal das Tecnologias e a atratividade da Distração Digital colaboram, positivamente, com o Uso Pessoal das Tecnologias durante o expediente de trabalho e convergem com outros estudos que apontam que características da dependência individual de TI são fatores que podem explicar o uso excessivo dos recursos tecnológicos em diferentes ambientes (Davis et al., 2002; Young, 1998).

Os resultados também evidenciam que o Conforto Online proporcionado pela utilização dos aplicativos também colabora de forma significativa para perda do controle do impulso sobre o Uso Pessoal da TI e, dessa forma, promove o aumento dos sintomas de dependência de tecnologias a que usuários podem estar sujeitos. Esquematicamente, o modelo de pesquisa e a síntese de seus resultados são representados conforme a Figura 2.

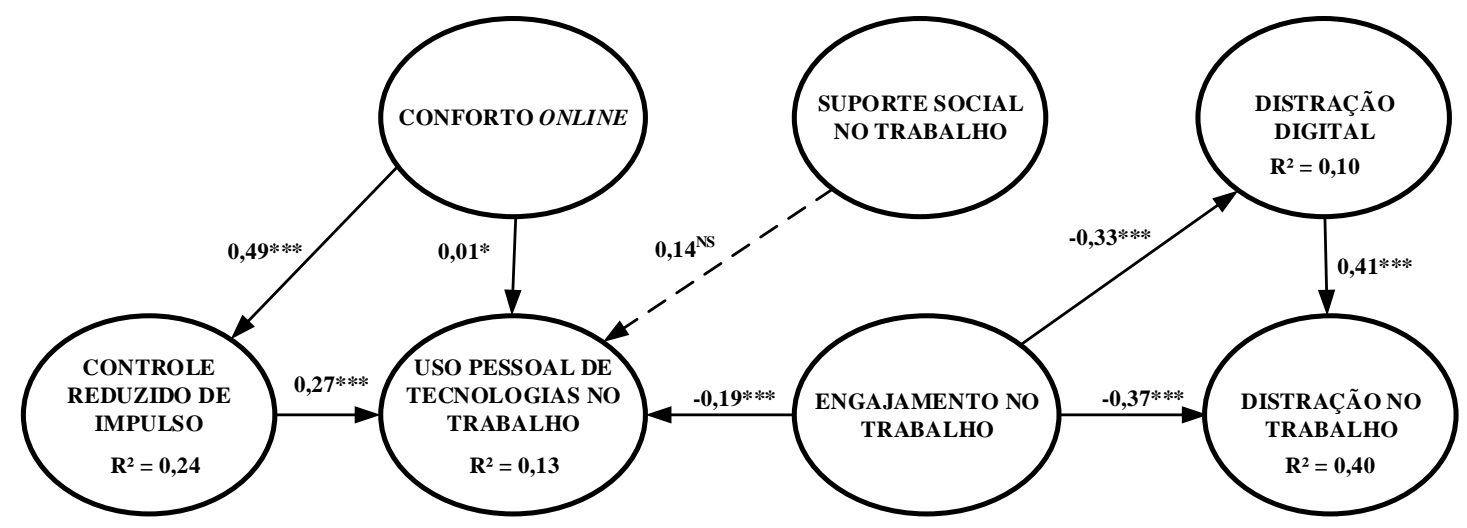

Figura 2. Resultados do Modelo Estrutural

$* * * \mathrm{p}<0,001 ; * \mathrm{p}<0,05$; seta tracejada (NS) = coeficiente não significante $(\mathrm{p}>0,05)$.

No entanto, os resultados obtidos mostram que o Conforto Online não se mostrou como um fator que promovesse o Uso Pessoal das Tecnologias na jornada de trabalho, embora existam diversos estudos que mostram que o Conforto Online seja um fator que motive a utilização de tecnologias (Ko et al., 2005; Mak et al., 2014). Uma possível explicação da falta de significância do Conforto Online com o Uso Pessoal da TI no Trabalho pode ser a presença de uma relação de mediação plena do Controle Reduzido de Impulso entre a associação do Conforto Online e o Uso Pessoal da TI no Trabalho. Nesse caso, recomenda-se que os relacionamentos entre construtos sejam recalculados sem a presença da variável mediadora (Baron \& Kenny, 1986; Edwards \& Lambert, 2007), no caso, Controle Reduzido de Impulso. A partir da suspeita de uma relação de mediação plena pelo Controle Reduzido de Impulso, procedeu-se novo cálculo sem a presença desse construto no modelo estrutural. Os valores dos coeficientes entre os construtos obtidos estão apresentados na Tabela 6. 
Tabela 6

Análise de Mediação Plena do Controle Reduzido de Impulso - Coeficientes do Modelo Estrutural

\begin{tabular}{lccccc}
\hline Relacionamentos & $\begin{array}{c}\text { Coeficientes } \\
\text { (Média) }\end{array}$ & $\begin{array}{c}\text { Desvio } \\
\text { Padrão }\end{array}$ & $\begin{array}{c}\text { Estatística } \\
\text { T }\end{array}$ & $\begin{array}{c}\text { p-valor } \\
\text { (bi-caudal) }\end{array}$ & FIV \\
\hline Conforto Online $\rightarrow$ Uso de TI & 0,15 & 0,06 & 2,42 & 0,02 & 1,02 \\
Distração Digital $\rightarrow$ Distração no Trabalho & 0,41 & 0,06 & 6,55 & 0,00 & 1,12 \\
Engajamento no Trabalho $\rightarrow$ Distração Digital & $-0,33$ & 0,06 & 5,39 & 0,00 & 1,00 \\
Engajamento no Trabalho $\rightarrow$ Distração no Trabalho & $-0,38$ & 0,05 & 7,21 & 0,00 & 1,12 \\
Engajamento no Trabalho $\rightarrow$ Uso de TI & $-0,25$ & 0,06 & 4,18 & 0,00 & 1,03 \\
Suporte Social no Trabalho $\rightarrow$ Uso de TI & 0,16 & 0,07 & 1,98 & 0,06 & 1,05 \\
\hline
\end{tabular}

De fato, a partir dos resultados da Tabela 6, observa-se que o Conforto Online é um dos fatores que promove o Uso Pessoal de TI e que essa associação é mediada pela perda de controle sobre o impulso de uso da tecnologia. Assim, evidencia-se que as sensações de conforto fornecidas pelos recursos pessoais de tecnologia promovem o uso pessoal durante o expediente profissional e convergem com estudos (Caplan, 2002; Davis et al., 2002) que as afirmam como um dos aspectos manifestados de usuários dependentes do Uso Pessoal da TI.

Após a obtenção dos coeficientes, conduziu-se a análise de detecção do viés do método comum devido à forma de coleta dos dados (Podsakoff \& Organ, 1986; Woszczynski \& Whitman, 2004). Recomenda-se o cálculo da razão da variância média substantivamente explicada pelos indicadores sobre a variância média devido ao método para detecção do viés citado (Liang, Saraf, Hu, \& Xue, 2007; Podsakoff, MacKenzie, Lee, \& Podsakoff, 2003). Nesse caso, a razão calculada da variância substantiva pela variância devida ao método foi igual a 123:1, o que torna improvável que o método de coleta de dados tenha sido responsável por algum viés nos resultados obtidos. Para análise de viés de endogeneidade por variáveis omitidas, calcularam-se as correlações de Pearson entre os escores padronizados das variáveis exógenas e os termos de erro das variáveis endógenas. Não foram detectadas correlações significativas, o que indica ausência desse viés nos resultados do estudo, segundo esse critério de avaliação (McIntosh, Edwards, \& Antonakis, 2014). Finalmente, após as validações apresentadas, apresenta-se a síntese dos testes de hipóteses do estudo na Tabela 7.

Tabela 7

\section{Síntese dos Testes de Hipóteses do Estudo}

\begin{tabular}{clc}
\hline Hipótese & Conteúdo & Resultado \\
\hline H1 & $\begin{array}{l}\text { A Distração Digital influencia positivamente a Distração no Trabalho. } \\
\text { H2 }\end{array}$ & $\begin{array}{l}\text { O Controle Reduzido de Impulso influencia positivamente o Uso Pessoal de } \\
\text { Tecnologias no Trabalho. }\end{array}$ \\
H3 & $\begin{array}{l}\text { O Conforto Online influencia positivamente o Uso Pessoal de Tecnologias no } \\
\text { Trabalho. }\end{array}$ & Confirmada \\
H4 & $\begin{array}{l}\text { O Conforto Online influencia positivamente o Controle Reduzido de Impulso. } \\
\text { H5 }\end{array}$ & $\begin{array}{l}\text { O Suporte Social no Trabalho influencia negativamente o Uso Pessoal de de } \\
\text { Tecnologias no Trabalho. }\end{array}$ \\
H6 & $\begin{array}{l}\text { O Engajamento no Trabalho influencia negativamente o Uso Pessoal de } \\
\text { Tecnologias no Trabalho. } \\
\text { H7 }\end{array}$ & \multicolumn{1}{c}{ Confirmada } \\
\end{tabular}

RAC, Rio de Janeiro, v. 21, n. 5, art. 1, pp. 605-626, Setembro/Outubro, 2017, www.anpad.org.br/rac (oc 


\section{Conclusões}

Algumas pessoas não conseguem imaginar a vida sem as Tecnologias de Informação e comunicação em seus negócios ou na vida privada, pela disponibilidade das diversas formas de aplicações, para interação social ou entretenimento.

Sabe-se que algumas empresas, inclusive, encorajam seus colaboradores a utilizar seus dispositivos pessoais como um fator de motivação para execução de suas atividades profissionais: tais políticas organizacionais são, geralmente, promovidas como campanhas com slogans traga seu próprio equipamento ou Bring Your Own Device (BYOD) (Schmitz, Teng, \& Webb, 2016).

Entretanto, apesar dos diversos benefícios que as tecnologias proporcionam aos seus usuários e às organizações, estudos têm demonstrado que a utilização intensa das tecnologias pessoais pode gerar consequências negativas aos usuários, advindas do seu uso indiscriminado e viciante (Armstrong et al., 2000; Brand et al., 2014).

Este estudo atingiu seu objetivo principal: analisar os aspectos individuais motivadores do uso particular de tecnologias no trabalho e evidenciar se a distração gerada pelos meios digitais pessoais pode ser considerada como um componente significativo à perda de atenção dos profissionais durante a execução de suas atividades laborais.

Para tanto, selecionaram-se fatores, potencialmente promotores do Uso Pessoal da TI no Trabalho, advindos de estudos que versam sobre sintomas de dependência tecnológica (Davis et al., 2002), além de aspectos que envolvem comportamento organizacional (Fredricks et al., 2004; Skinner et al., 2008) e influências sociais (Marshall et al., 2007).

A primeira conclusão deste estudo evidencia que fatores individuais ligados à dependência tecnológica motivam o Uso Pessoal das Tecnologias no Trabalho. Entre esses aspectos, observou-se que a perda do controle sob o impulso de uso da TI é o fator antecedente mais significativo ao Uso Pessoal das Tecnologias, comparada a fatores como o Conforto Online, à Distração Digital e a outros aspectos analisados nesta pesquisa.

Nesse sentido, o estudo confirma que a dependência de uso das tecnologias interfere diretamente no desempenho profissional dos seus usuários, pois a perda de controle sobre o impulso de uso da TI provoca a interrupção da execução das atividades orientadas às demandas organizacionais e, por consequência, a redução da produtividade individual. Particularmente, este é um resultado interessante, pois a utilização indevida dos dispositivos pessoais nas organizações pode ser motivada por um desejo pessoal suficiente para que o usuário infrinja políticas organizacionais internas e desrespeite restrições gerenciais que governem o comportamento de uso de seus dispositivos pessoais no ambiente de trabalho.

Como a perda de controle do impulso é um sintoma individual de dependência tecnológica que demanda auxílio externo para a contenção dos comportamentos abusivos (Young, 2011), tal descoberta sugere que a gerência exerça papel determinante em atividades, ou na elaboração de controles internos que adequem o uso privado da TI dos profissionais durante o expediente profissional de forma a eliminar possíveis perdas de produtividade dos seus colaboradores.

Os resultados também mostram que a sensação de segurança e conforto que a tecnologia de uso pessoal proporciona ao usuário reforça a perda de controle sobre o impulso de uso dessas tecnologias. Assim, entende-se que a implantação de políticas organizacionais de restrição total à utilização particular de tecnologias pode gerar inquietações e insatisfações no ambiente de trabalho, por conta da redução das sensações positivas proporcionadas, entre outras razões, pelo Conforto Online percebido pelos usuários.

Portanto, conter a distração eletrônica dos seus colaboradores pode ser mais um desafio colocado aos gestores das organizações na Era da Informação: a possibilidade de restringir o acesso aos recursos 
tecnológicos privados dos colaboradores sob a forma de políticas internas organizacionais pode ser problemática ao gestor, dadas as evidências encontradas sobre o Uso Pessoal da TI no Trabalho estar ligado a fatores associados com a dependência individual tecnológica, à qual os seus profissionais já podem estar submetidos.

A partir desses resultados, recomenda-se que a implantação de programas de restrição ao uso particular de tecnologias nas organizações seja precedida de campanhas organizacionais de conscientização dos colaboradores sobre os potenciais efeitos adversos do uso particular e abusivo da TI, como uma tentativa de atenuação dos dissabores potenciais da restrição do uso de tecnologias privadas por estes mesmos colaboradores.

A perda de controle do impulso de uso da TI, a Distração Digital e o Conforto Online Percebido são claras evidências da necessidade de ações externas que supervisionem o uso excessivo das tecnologias pelos colaboradores, pois o usuário, por si só, pode ter dificuldade em adequar o uso privado da TI com as suas responsabilidades cotidianas, dada a sua alta dependência em relação à TI (Young, 2004, 2011).

O estudo também revelou que a utilização pessoal da TI no ambiente de trabalho e a Distração Digital são reflexos diretos da redução do Engajamento do profissional no cumprimento de suas tarefas cotidianas. Assim, os resultados deste estudo mostram que o uso abusivo das tecnologias também pode ser consequência da desmotivação do colaborador para a finalização das suas demandas profissionais. Logo, comportamentos abusivos no uso da TI pelos colaboradores podem ser considerados sinais de alerta para os gestores sobre o comprometimento profissional reduzido de alguns membros das equipes de trabalho, além dos aspectos ligados à dependência tecnológica dos usuários.

A partir da detecção da baixa motivação profissional pelo uso abusivo da TI, ações gerenciais que promovam a motivação do funcionário (Tamayo \& Paschoal, 2003) podem ser efetivadas para reduzir comportamentos negativos que culminem na demissão ou na saída voluntária do colaborador.

Este estudo confirma que a Distração Digital provoca perda de concentração dos profissionais no trabalho. Sabe-se que a utilização de Tis pode levar o usuário a experimentar as sensações de fluxo e, por consequência, não perceber o tempo de uso em suas aplicações pessoais, por conta dessas sensações (Agarwal \& Karahanna, 2000; Koufaris, 2002).

Como implicação prática, sugere-se que as campanhas de conscientização sobre os efeitos adversos do uso excessivo de TI orientem que os colaboradores alertem diretamente os seus pares quando notarem utilização excessiva da TI por alguns colegas, e ilustrem os efeitos negativos percebidos das tecnologias nas atividades profissionais do usuário, dada a possibilidade dos próprios usuários não perceberem o uso abusivo dos seus dispositivos durante o expediente, pela distração ou sensação de fluxo.

Embora a preferência de uso dos aplicativos pessoais, segundo os participantes da pesquisa, sejam os sistemas que promovem interação social, tais como as redes sociais e os sistemas de comunicação instantânea, a pesquisa não evidenciou que o uso particular dessas aplicações serviria como subterfúgio dos profissionais que contam com Suporte Social reduzido no local de trabalho. Em outras palavras, os resultados encontrados não permitem afirmar que fracos vínculos afetivos entre os profissionais da organização promovam a utilização indiscriminada de TI, inclusive, dos aplicativos de comunicação.

Ao contrário, o relacionamento positivo entre Suporte Social e Uso Pessoal da TI no Trabalho, embora com significância comprometida, indica uma provável influência do Suporte Social na promoção do Uso Pessoal da TI. Uma possível justificativa para esse resultado é a utilização dos dispositivos pessoais como meio de interação frequente e facilitador das relações sociais entre os pares durante a jornada de trabalho.

Além disso, detectada a baixa correlação entre o uso privado de TI no trabalho e o Suporte Social, evidencia-se que os problemas de relacionamento entre grupos em ambientes organizacionais não são fruto de uso demasiado de tecnologias pessoais. Desse modo, entende-se que políticas organizacionais 
de restrição ao uso privado de tecnologias não devem influenciar melhorias significativas no relacionamento entre os pares da organização.

Esta pesquisa contribui para a utilização e o desenvolvimento de instrumentos de medida de uso problemático de tecnologias no Brasil, com a apresentação das validações dos indicadores obtidos de escalas internacionais e sob o aspecto da validade nomológica, pela significância obtida dos relacionamentos entre os construtos de dependência tecnológica aos construtos ligados ao comportamento organizacional.

Este estudo também contribui para apresentar os efeitos negativos das tecnologias pessoais nas organizações, pois a literatura que trata dos temas ligados à área de dependência tecnológica apresenta, em sua maioria, artigos que buscam identificar grupos sujeitos à dependência tecnológica ou sintomas de dependência que permitam o diagnóstico de profissionais da área da saúde, que possam auxiliar o tratamento do vício em Tecnologias de Informação, entre outras possibilidades.

Entretanto, não se pretende com este artigo esgotar as possibilidades de conclusões sobre tema, pois o uso intensivo e a popularidade das tecnologias em públicos de distintas faixas etárias e classes sociais proporcionam diversas oportunidades de investigação ligadas ao Uso Pessoal excessivo de Tecnologias em múltiplos contextos de utilização. Por exemplo, observa-se que o poder de explicação $\left(\mathrm{r}^{2}\right)$ encontrado na relação entre as variáveis de Distração Digital e Engajamento sobre a Distração no Trabalho apresentou valor igual a $48 \%$. Embora seja um valor considerado alto, acredita-se que outras distrações no ambiente de trabalho, como conversas paralelas dentro da equipe, ambiente com ruídos excessivos, problemas pessoais e emocionais contribuam para a redução da concentração profissional e possam acrescer a explicação das causas de Distração profissional.

Além disso, desconhece-se qual a contribuição da Distração no Trabalho pela sinalização de notificações das próprias aplicações que chamam a atenção do usuário, comparada ao comportamento ativo do usuário em acessar os seus aplicativos voluntariamente.

O estudo possui limitações que não podem ser desconsideradas. Por exemplo, a presença de erros de medida por meio de imprecisão na mensuração dos valores reais das respostas. Logo, vislumbra-se outra possibilidade de pesquisa que envolva o monitoramento real dos usuários com aplicativos que gerenciem o tempo dispendido com tecnologias pessoais, com o objetivo de captar dados e aumentar a precisão dos efeitos desses recursos nas suas atividades laborais. A partir da coleta desses dados, existe a possibilidade de análise, transversal e longitudinal, dos efeitos da implantação de políticas organizacionais de restrição de acesso às tecnologias pessoais, inclusive, entre grupos de usuários.

A generalização dos resultados dessa amostra à população de profissionais que utilizam tecnologias também é outra fraqueza do estudo. Sob o ponto de vista do perfil da amostra, entende-se que é possível a obtenção de diferenças nos resultados a partir de análise de grupos profissionais com formação, experiências e funções diversas, ou que atuem em diferentes setores organizacionais. Sob o ponto de vista da coleta dos dados ter sido realizada em um único estado no Brasil, não se pode afirmar que os resultados se mantenham constantes, dadas as diferenças de infraestrutura em outras regiões do país, que podem impactar em diferenças na facilidade de acesso à rede pública de dados pelos usuários.

\section{Agradecimentos}

Os autores agradecem à Fundação de Amparo à Pesquisa do Estado de São Paulo (FAPESP) pela concessão de recursos para viabilidade da pesquisa (Processo 2015/22795-0). 


\section{Referências}

Agarwal, R., \& Karahanna, E. (2000). Time flies when you're having fun: Cognitive absorption and beliefs about information technology usage. MIS Quarterly, 24(4), 665-694. http://dx.doi.org/10.2307/3250951

American Psychiatric Association. (2014). Diagnostic and statistical manual of mental disorders (5th ed.). Arlington, VA: Author.

Armstrong, L., Phillips, J. G., \& Saling, L. L. (2000). Potential determinants of heavier internet usage. International Journal of Human-Computer Studies, 53(4), 537-550. http://dx.doi.org/10.1006/ijhc.2000.0400

Bakker, A. B., Albrecht, S. L., \& Leiter, M. P. (2011). Key questions regarding work engagement. European Journal of Work and Organizational Psychology, 20(1), 4-28. http://dx.doi.org/10.1080/1359432X.2010.485352

Bargh, J. A., \& Mckenna, K. Y. A. (2004). The internet and social life. Annual Review of Psychology, 55, 576-590. http://dx.doi.org/10.1146/annurev.psych.55.090902.141922

Barifouse, R. (2015). O smartphone vai matar o celular “comum”? São Paulo: BBC Brasil.

Baron, R. M., \& Kenny, D. A. (1986). The moderator-mediator variable distinction in social psychological research: Conceptual, strategic, and statistical considerations. Journal of Personality and Social Psychology, 51(6), 1173-1182.

Brand, M., Laier, C., \& Young, K. S. (2014). Internet addiction: Coping styles, expectancies, and treatment implications. Frontiers in Psychology, 5, 1-14. http://dx.doi.org/10.3389/fpsyg.2014.01256

Caplan, S. E. (2002). Problematic internet use and psychosocial well-being: Development of a theorybased cog.-beh. measurement instrument. Computers in Human Behavior, 18(5), 553-575. http://dx.doi.org/10.1016/S0747-5632(02)00004-3

Chin, W. W. (1998). The PLS approach to SEM. In G. A. Marcoulides (Org.), Modern methods for business research (pp. 295-358). Mahwah, NJ: Lawrence Erlbaum.

Chin, W. W., \& Newsted, P. R. (1999). Structural equation modeling analysis with small samples using partial least squares. In R. H. Hoyle (Org.), Statistical strategies for small sample research (pp. 307-341). Thousand Oaks, CA: Sage Publications.

Churchill, G. A. (1979). A paradigm for developing better measures of marketing constructs. Journal of Marketing Research, 16(1), 64-73. http://dx.doi.org/10.2307/3150876

Cohen, J. (1988). Statistical power analysis for the behavioral sciences (2nd ed.). Hillsdale, NJ: Erlbaum.

Cronbach, L. J., \& Meehl, P. E. (1955). Construct validity in psychological tests. Psychological Bulletin, 52(4), 281-302.

Davis, R. A. (2001). Cognitive-behavioral model of pathological internet use. Computers in Human Behavior, 17(2), 187-195. http://dx.doi.org/10.1016/S0747-5632(00)00041-8

Davis, R. A., Flett, G. L., \& Besser, A. (2002). Validation of a new scale for measuring problematic internet use: Implications for pre-employment screening. CyberPsychology \& Behavior, 5(4), 331-345. http://dx.doi.org/10.1089/109493102760275581 
Diamantopoulos A., \& Siguaw J. A. (2006). Formative versus reflective indicators in organizational measure development: A comparison and empirical illustration. British Journal of Management, 17(4), 263-282. http://dx.doi.org/10.1111/j.1467-8551.2006.00500.x

Edwards, J. R., \& Lambert, L. S. (2007). Methods for integrating moderation: A general analytical framework using moderated path analysis. Psychological Methods, 12(1), 1-22. http://dx.doi.org/10.1037/1082-989X.12.1.1

Efron, B., \& Tibshirani, R. J. (1998). An introduction to the bootstrap. Boca Raton, FL: Chapman \& Hall / CRC Press.

Emarketer (2014). Internet hit 3 billion users in 2015. New York City, NY: eMarketer.

Faul, F., Erdfelder, E., Buchner, A., \& Lang, A. G. (2009). Statistical power analyses using G*Power 3.1: Tests for correlation and regression analyses. Behavior Research Methods, 41(4), 1149-1160. http://dx.doi.org/10.3758/BRM.41.4.1149

Fornell, C., \& Larcker, D. F. (1981). Evaluating structural equation models with unobservable variables and measurement error. Journal of Marketing Research, 18(1), 39-50. http://dx.doi.org/10.2307/3151312

Fredricks, J. A., Blumenfeld, P. C., \& Paris, A. H. (2004). School engagement: potential of the concept, state of the evidence. Review of Educational Research, 74(1), 59-109. https://doi.org/10.3102/00346543074001059

Ghani, J. A., \& Deshpande, S. P. (1994). Task characteristics and the experience of optimal flow in human-computer interaction. The Journal of Psychology, 128(4), 381-391. http://dx.doi.org/10.1080/00223980.1994.9712742

Goleman, D. (2013). Foco: A atenção e seu papel fundamental para o sucesso. Rio de Janeiro, RJ: Objetiva.

Greenfield, D. N., \& Davis, R. A. (2002). Lost in cyberspace: The web @ work. Cyberpsychology \& Behavior, 5(4), 347-353. http://dx.doi.org/10.1089/109493102760275590

Hair, J. F., Black, W. C., Babin, B. J., Anderson, R. E., \& Tatham, R. L. (2009). Análise multivariada de dados (6a ed.). Porto Alegre: Bookman.

Hair, J. F., Hult, G. T. M., Ringle, C. M., \& Sarstedt, M. (2014). A primer on partial least squares structural equation modeling (PLS-SEM). Thousand Oaks, CA: SAGE Publications.

Huang, H., \& Leung, L. (2009). Instant messaging addiction among teenagers in China: Shyness, alienation, and academic performance decrement. Cyberpsychology \& Behavior, 12(6), 675-679. http://dx.doi.org/10.1089/cpb.2009.0060

Jarvis, C. B, Mackenzie S. B., \& Podsakoff P. M. (2003). A critical review of construct indicators and measurement model misspecification in marketing and consumer research. Journal of Consumer Research, 30(2), 199-218. http://dx.doi.org/10.1086/376806

King, A. L. S., Valença, A. M., Silva, A. C. O., Baczynski, T., Carvalho, M. R., \& Nardi, A. E. (2013). Nomophobia: Dependency on virtual environments or social phobia? Computers in HB, 29(1), 140-144. http://dx.doi.org/10.1016/j.chb.2012.07.025

Ko, C.-H., Yen, C.-F., Yen, C.-N., Yen, J.-Y., Chen, C.-C., \& Chen, S.-H. (2005). Screening for internet addiction: An empirical study on cut-off points for the Chen internet addiction scale. The Kaohsiung Journal of Medical Sciences, 21(12), 545-551. http://dx.doi.org/10.1016/S1607551X(09)70206-2 
Koufaris, M. (2002). Applying the technology acceptance model and flow theory to online consumer behavior. Information Systems Research, 13(2), 205-223. http://dx.doi.org/10.1287/isre.13.2.205.83

Lee, S. M., \& Chen, L. (2010). The impact of flow on online consumer behavior. Journal of Computer Information Systems, 50(4), 1-10.

Lee, Y. K., Chuang, C. T., \& Cheng, Z. H. (2014). The dark side of smartphone usage: Psychological traits, compulsive behavior and technostress. Computers in Human Behavior, 31, 373-383. http://dx.doi.org/10.1016/j.chb.2013.10.047

Liang, H., Saraf, N., Hu, Q., \& Xue, Y. (2007). Assimilation of ES: The effect of institutional pressures and the mediating role of top management. MIS Quarterly, 31(1), 59-87.

Mak, K.-K., Lai E. C.-M., Ko, C.-H., \& Ho, R. C. M. (2014). Psychometric properties of the revised Chen internet addiction scale (CIAS-R) in Chinese adolescents. Journal of Abnormal Child Psychology, 42(7), 1237-1245. http://dx.doi.org/10.1007/s10802-014-9851-3

Marshall, G. W., Michaels, C. E., \& Mulki, J. P. (2007). Workplace isolation: Exploring the construct and its measurement. Psychology \& Marketing, 24(3), 195-223. http://dx.doi.org/10.1002/mar.20158

Maslach, C., \& Leiter, M. P. (1997). The truth about burnout: How organizations cause personal stress and what to do about it. San Francisco: Jossey-Bass.

McIntosh, C., Edwards, J., \& Antonakis, J. (2014). Reflections on PLS path modeling. Organizational Research Models, 17(2), 210-251. https://doi.org/10.1177/1094428114529165

Netemeyer, R. G., Bearden, W. O., \& Sharma, S. (2003). Scaling procedures: Issues and applications. Thousand Oaks, CA: Sage Publications.

Nunally, J. C., \& Bernstein, I. (1994). Psychometric theory. New York, NY: McGraw-Hill.

Pinsonneault, A., \& Kraemer K. L. (1993). Survey research methodology in management information systems: An assessment. Journal of Management Information Systems, 10(2), 75-105.

Podsakoff, P. M., MacKenzie, S. B., Lee, J.-Y., \& Podsakoff, N. P. (2003). Common method biases in behavioral research: A critical review of the literature and recommended remedies. Journal of Applied Psychology, 88(5), 879-890. http://dx.doi.org/10.1037/0021-9010.88.5.879

Podsakoff, P. M., \& Organ, D. W. (1986). Self-reports in organizational research: Problems and prospects. Journal of Management, 12(4), 531-544.

Ringle, C. M., Wende, S., \& Becker, J. (2015). SmartPLS 3. Bönningstedt: SmartPLS.

Salehan, M., \& Negahban, A. (2013). Social networking on smartphones: When mobile phones become addictive. Computers in Human Behavior, 29(6), 2632-2639. http://dx.doi.org/10.1016/j.chb.2013.07.003

Schmitz, K. W., Teng, J. T. C., \& Webb, K. J. (2016). Capturing the complexity of malleable it use: Adaptive structuration theory for individuals, MIS Quarterly, 40(3), 663-686.

Shikiar, R., Halpern, M. T., Rentz, A. M., \& Khan, Z. M. (2004). Development of the health and work questionnaire (HWQ): An instrument for assessing workplace productivity in relation to worker health. WORK: A Journal of Prevention, Assessment \& Rehabilitation, 22(3), 219-229. 
Siqueira, M. M. M., Martins, M. C. F., Orengo, V., \& Souza, W. S. (2014). Engajamento no trabalho. In M. M. M. Siqueira (Org.), Novas medidas do comportamento organizacional (pp. 147-154). Porto Alegre, Artmed.

Simsion, G. (2007). Data modeling: Theory and practice. Melbourne: Technics Publications.

Skinner, E. A., Furrer, C., Marchand, G., \& Kindermann, T. (2008). Engagement and disaffection in the classroom: Part of a larger motivational dynamic? Journal of Educational Psychology, 100(4), 765-781. http://dx.doi.org/10.1037/a0012840

Spada, M. (2014). An overview of problematic internet use. Addictive Behaviors, 39(1), 3-6. http://dx.doi.org/10.1016/j.addbeh.2013.09.007

Suedfeld, P. (1977). Loneliness: The experience of emotional and social isolation. Behaviour Therapy, 8(1), 120-121. http://dx.doi.org/10.1016/S0005-7894(77)80143-3

Sultan, A. (2014). Addiction to mobile text messaging applications is nothing to "lol" about. The Social Science Journal, 51(1), 57-69. http://dx.doi.org/10.1016/j.soscij.2013.09.003

Tamayo, A., \& Paschoal, T. (2003). A relação de motivação para o trabalho com as metas do trabalhador. Revista de Administração Contemporânea, 7(4), 33-54. http://dx.doi.org/10.1590/S141565552003000400003

Werts, C., Linn, R., \& Jöreskog, K. (1974). Intraclass reliability estimates: Testing structural assumptions. Educational and Psychological Measurement, 34(1), 25-33. http://dx.doi.org/10.1177/001316447403400104

Whitty, M. T., \& Carr, A. N. (2006). New rules in the workplace: Applying object-relations theory to explain problem Internet and email behaviour in the workplace. Computers in Human Behavior, 22(2), 235-250. http://dx.doi.org/10.1016/j.chb.2004.06.005

Widyanto, L., Griffiths, M. D., \& Brunsden, V. (2011). A psychometric comparison of the internet addiction test, the internet-related problem scale, and self-diagnosis. CyberPsychology \& Behavior, 14(3), 141-149. http://dx.doi.org/10.1089/cyber.2010.0151

Widyanto, L., \& McMurran, M. (2004). The psychometric properties of the internet addiction test. CyberPsychology \& Behavior, 7(4), 443-450. http://dx.doi.org/10.1089/cpb.2004.7.443

Woszczynski, A. M., \& Whitman, M. E. (2004). The problem of common method variance in IS research. In M. E. Whitman \& A. M. Woszczynski (Eds.), The handbook of information systems research (Chap. V, pp. 66-77). Hershey, PA: Idea Group Publishing.

Yao, M. Z., \& Zhong, Z. J. (2014). Loneliness, social contacts and Internet addiction: A cross-lagged panel study. Computers in HB, 30, 164-170. http://dx.doi.org/10.1016/j.chb.2013.08.007

Young, K. S. (1998). Caught in the net: How to recognize the signs of Internet addiction - and a winning strategy for recovery. Hoboken, NJ: John Wiley \& Sons, Inc.

Young, K. S. (2004). Internet addiction: A new clinical phenomenon and its consequences. American Behavioral Scientist, 48(4), 402-415. http://dx.doi.org/10.1177/0002764204270278

Young, K. S. (2009). Internet addiction: The emergence of a new clinical disorder. CyberPsychology \& Behavior, 1(3), 237-244. http://dx.doi.org/10.1089/cpb.1998.1.237 (1st ed. Published of 1998)

Young, K. S. (2011). CBT-IA: The first treatment model for internet addiction. Journal of Cognitive Psychotherapy, 25(4), 304-312. https://doi.org/10.1891/0889-8391.25.4.304 
Young, K. S., \& Rogers, R. C. (2009). The relationship between depression and internet addiction. CyberPsychology \& Behavior, 1(1), 25-58. http://dx.doi.org/10.1089/cpb.1998.1.25 (1st ed. Published of 1998)

\title{
Dados dos Autores
}

\author{
Alexandre Cappellozza \\ Rua Alfeu Tavares, 149, Rudge Ramos, 09641-000, São Bernardo do Campo, SP, Brasil: E-mail: \\ alexandre.cappellozza@metodista.br \\ Gustavo Hermínio Salati Marcondes de Moraes \\ Rua Pedro Zaccaria, 1300, Jardim Santa Luiza, 13484-350, Limeira, SP, Brasil. E-mail: gustavo.salati@ fca.unicamp.br \\ Leonardo Mairene Muniz \\ Rua Alfeu Tavares, 149, Rudge Ramos, 09641-000, São Bernardo do Campo, SP, Brasil: E-mail: leonardo.muniz@ metodista.br
}

